\title{
Reduction of $\mathrm{UH}^{+}$formation for ${ }^{236} \mathrm{U} /{ }^{238} \mathrm{U}$ isotope ratio measurements at ultratrace level in double focusing sector field ICP-MS using $\mathrm{D}_{2} \mathrm{O}$ as solvent
}

\author{
M. V. Zoriy, ${ }^{a, d}$ L. Halicz, ${ }^{b}$ M. E. Ketterer ${ }^{c}$ C. Pickhardt, ${ }^{a}$ P. Ostapczuk ${ }^{d}$ and \\ J. S. Becker*a \\ ${ }^{a}$ Central Division of Analytical Chemistry, Research Centre Juelich, D-52425 Jülich, \\ Germany.E-mail: s.becker@fz-juelich.de \\ ${ }^{b}$ Geological Survey of Israel, Jerusalem 95901, Israel \\ ${ }^{c}$ Northern Arizona University, Department of Chemistry, Flagstaff, AZ 86011-5698, USA \\ ${ }^{d}$ Department for Safety and Radiation Protection, Research Centre in Jülich, \\ $D-52425$ Jülich, Germany
}

Received 10th November 2003, Accepted 5th January 2004

First published as an Advance Article on the web 13th February 2004

\begin{abstract}
The main factors affecting the accurate and precise determination of ${ }^{236} \mathrm{U}$ using ICP-MS are instrumental background, the isobaric interference of ${ }^{235} \mathrm{UH}^{+}$molecular ion on ${ }^{236} \mathrm{U}^{+}$analyte ions, and the presence of ${ }^{238} \mathrm{U}^{+}$and ${ }^{235} \mathrm{U}^{+}$peak tails. An optimized analytical method for attenuating the influence of these factors on uranium isotope ratio measurements at ultratrace level of environmental samples has been developed. In order to reduce ${ }^{235} \mathrm{UH}^{+}$formation, $\mathrm{D}_{2} \mathrm{O}$ (heavy water) is used as a solvent for the dissolution and dilution of uranium samples. Abundance sensitivity was improved by use of medium mass resolution $(m / \Delta m=4450)$ in comparison with low mass resolution in double-focusing sector field ICP-MS (ICP-SFMS). For solution introduction the performances of several different sample introduction systems (Meinhard, Aridus and ultrasonic nebulizer) were studied. It has been shown, that for all nebulization systems, a diminution in $\mathrm{UH}^{+} / \mathrm{U}^{+}$is observed in $\mathrm{D}_{2} \mathrm{O}$ as compared with $\mathrm{H}_{2} \mathrm{O}$ as solvent. Optimum results were obtained in ICP-SFMS for a desolvating microconcentric nebulizer system (Aridus) with a minimum hydride formation rate of $9 \times 10^{-7}$ and a limit for ${ }^{236} \mathrm{U} /{ }^{238} \mathrm{U}$ isotopic ratio measurements of $3-5 \times 10^{-7}$. A comparison was performed of three commercially available sector field ICP-MS devices, with good agreement found between single collector and multiple collector ICP-MS (MC-ICP-MS).
\end{abstract}

\section{Introduction}

Determination of the concentration and isotopic analysis of uranium at trace and ultratrace levels is of increasing interest for environmental monitoring, nuclear safeguards and nuclear forensic studies. ${ }^{1-3}$ In addition to analysis of natural uranium isotopes, determination of ${ }^{236} \mathrm{U}$ is a challenging task. ${ }^{4-6}$ In nature, uranium occurs in the Earth's crust and in sea-water, at around $2.7 \mathrm{ppm}$ and $3.0 \mathrm{ppb}$, respectively. ${ }^{7}$ The uranium isotopes of primordial origin are ${ }^{238} \mathrm{U}$ and ${ }^{235} \mathrm{U}$ with abundances of $99.27 \%$ and $0.72 \%$, respectively. ${ }^{234} \mathrm{U}$ in nature is produced from the ${ }^{238} \mathrm{U}$ decay series, with an abundance of $0.005 \%$, and is approximately in radioactive equilibrium with ${ }^{238} \mathrm{U}$. ${ }^{236} \mathrm{U}$, which is generated by neutron capture from ${ }^{235} \mathrm{U}$ (the neutrons are obtained from $(\alpha, n)$ reactions, spontaneous fission of ${ }^{238} \mathrm{U}$ ) and from interaction of cosmic rays with matter, is present in the natural Earth's crust at ultratrace levels. ${ }^{8}$ The natural abundance of ${ }^{236} \mathrm{U}$ is highest in U-rich materials, and several studies have demonstrated that the ${ }^{236} \mathrm{U}^{238} \mathrm{U}$ isotopic ratio is of the order of $10^{-10}$ in $\mathrm{U}$ ores. ${ }^{9-11} \mathrm{~A}$ ${ }^{236} \mathrm{U} /{ }^{238} \mathrm{U}$ isotopic ratio of the order of $10^{-13}-10^{-14}$ is expected in the Earth's crust. ${ }^{12}$ However, enhanced levels of ${ }^{236} \mathrm{U}$ are produced (in the past $\sim 50$ years) in nuclear reactors by the neutron irradiation of ${ }^{235} \mathrm{U}:{ }^{235} \mathrm{U}+{ }^{1} \mathrm{n} \rightarrow{ }^{236} \mathrm{U}$ (with a cross section of 95 barns for thermal neutrons versus fission cross section of 586 barns). As a result, the ${ }^{236} \mathrm{U} /{ }^{238} \mathrm{U}$ isotopic ratio increases to up to $10^{-3}-10^{-2}$, and the ${ }^{236} \mathrm{U}$ has a "poisoning" effect upon the fission of ${ }^{235} \mathrm{U}^{8}$ Recovered reactor-irradiated $\mathrm{U}$ contains ${ }^{236} \mathrm{U}$ and its presence has been confirmed in depleted uranium; ${ }^{12-14}$ artificial ${ }^{236} U$ has been identified in Chernobyl-vicinity soils, ${ }^{4}$ several other environmental sites, ${ }^{5}$ and in the NBS standard reference materials (SRM) 950a and $950 \mathrm{~b} .{ }^{10}$ The determination of ${ }^{236} \mathrm{U}$, therefore, can be used as a powerful tool for "fingerprinting" of artificial uranium in environmental samples. Large increases in the ${ }^{236} \mathrm{U} /{ }^{238} \mathrm{U}$ isotopic ratio represent a much more sensitive indicator of the presence of irradiated uranium than small deviations in ${ }^{235} \mathrm{U} /{ }^{238} \mathrm{U}$ from its value in nature $(0.00725)$. Thus, according to the different studies, ${ }^{15,16}$ the estimated ${ }^{235} \mathrm{U} /{ }^{238} \mathrm{U}$ isotopic ratio in spent uranium of the Chernobyl reactor varies from 0.0067 to 0.0084 , which makes difficult accurate determination of the spent uranium in contaminated soil samples by measuring ${ }^{235} \mathrm{U} /{ }^{238} \mathrm{U}$ isotopic ratio. The accurate measurement of ${ }^{236} \mathrm{U} /{ }^{238} \mathrm{U}$ isotopic ratio, therefore, is of great importance as evidence of contamination of environmental samples with uranium from nuclear reactors, reprocessing plants, or other anthropogenic sources.

In recent years, several approaches have been utilized for ${ }^{236} U /{ }^{238} U$ isotopic ratio measurements. Since ${ }^{236} U$ decays by alpha-emission, with alpha-particle energies, $E_{\alpha}$, of $4.494 \mathrm{MeV}$ (74\%) and $4.445 \mathrm{MeV}(26 \%),{ }^{17}$ alpha spectrometry has been used in most laboratories. ${ }^{6,14,18}$ However, ${ }^{236} \mathrm{U}$ has a relatively low specific activity, and its alpha particle energies are relatively close to ${ }^{235} \mathrm{U}$, which exhibits decay energies of $4.502 \mathrm{MeV}$ (relative intensity $1.7 \%$ ) and $4.435 \mathrm{MeV}$ (relative intensity $0.7 \%) .{ }^{17}$ Compared with decay-counting techniques, mass spectrometry is advantageous due to its high sensitivity and the possibility of measuring isotope ratios with good accuracy and precision for determination of long-lived nuclides. ${ }^{1,19}$ Thermal ionization mass spectrometry (TIMS) ${ }^{20-22}$ and accelerator mass spectrometry (AMS) ${ }^{7,8,23}$ are well-established techniques for uranium isotope ratio measurements at the ultratrace level. 
Measurements of ${ }^{236} \mathrm{U} /{ }^{238} \mathrm{U}$ isotopic ratio down to $10^{-12}$ are feasible by AMS, ${ }^{24}$ but the capital costs and centralized placement of AMS facilities restrict its use to specialized applications. Inductively coupled plasma mass spectrometry (ICP-MS) exhibits high sensitivity, good accuracy and precision of isotopic measurement and a relatively simple sample preparation procedure; ${ }^{25,26}$ arguably, ICP-MS is one of the most suitable methods for routine uranium isotope ratio measurement in environmental samples. ${ }^{27-29}$ However, the determination of ${ }^{236} \mathrm{U}$ by ICP-MS is constrained by isobaric interference from ${ }^{235} \mathrm{U}^{1} \mathrm{H}^{+}, 4,5,30$ as well as the limited abundance sensitivity of ICP-MS instruments. ${ }^{31-33}$ Both of these effects result in increases in the background signal at $\mathrm{m} / \mathrm{z} 236$. The abundance sensitivity arises from overlap of ${ }^{235} \mathrm{U}$ and ${ }^{238} \mathrm{U}$ peak tails, and is especially problematic in sector field ICP-MS at low mass resolution. As an example, Boulyga and Becker ${ }^{34}$ found an abundance sensitivity at $\mathrm{m} / \mathrm{z}=236$ of $6 \times 10^{-8}$ in quadrupole ICP-MS with hexapole collision cell, exhibiting an abundance sensitivity up to two orders of magnitude better, which was ruled to be preferential. It is, however, possible to improve the abundance sensitivity in ICP-SFMS at medium or high mass resolution; Ketterer et al. ${ }^{5}$ obtained an abundance sensitivity of $5 \times 10^{-8}$ at $\mathrm{m} / \mathrm{z}=236$ in the presence of ${ }^{238} \mathrm{U}$ by using medium mass resolution $(\mathrm{m} / \Delta m=3440)$ in ICPSFMS. In a recent study, ${ }^{35}$ an ICP-QMS device equipped with a hexapole collision cell was used to investigate uranium isotopic compositions in soils from the relocation zone of Belarus near the Chernobyl reactor. Application of ultrasonic nebulizer and membrane desolvator allowed the achievement of a relatively low uranium hydride formation rate of $\mathrm{UH}^{+} / \mathrm{U}^{+}$of $\sim 2 \times 10^{-6}$. This performance was more than adequate for analysis of Chernobyl-area samples, which exhibited ${ }^{236} \mathrm{U} /{ }^{238} \mathrm{U}$ isotopic ratio ranging from 0.058 to $0.972 \times 10^{-3}$

The determination of low ${ }^{236} \mathrm{U}^{238} \mathrm{U}$ isotopic ratios would benefit from attenuation of $\mathrm{UH}^{+}$formation: therefore, in the present study, $\mathrm{D}_{2} \mathrm{O}$ (heavy water) as a solvent was investigated because a suppression of $\mathrm{UH}^{+}$formation using $\mathrm{D}_{2} \mathrm{O}$ relative to $\mathrm{H}_{2} \mathrm{O}$ was expected. The abundance sensitivity and figures of merit of ICP-SFMS were investigated in both solvents using a $\mathrm{U}$ standard reference, and the developed method in $\mathrm{D}_{2} \mathrm{O}$ was applied to measurements of ${ }^{236} \mathrm{U}^{238} \mathrm{U}$ isotopic ratios in natural samples from Israel.

\section{Experimental}

\section{ICP-MS instrumentation}

A double-focusing sector field ICP-MS with reverse Nier-Johnson geometry (ICP-SFMS, ELEMENT, Thermo Finnigan MAT, Bremen, Germany) was used for ${ }^{236} \mathrm{U} /{ }^{238} \mathrm{U}$ isotopic ratio measurements in the Central Division of Analytical Chemistry at Research Centre Juelich. For solution introduction, three nebulizers were utilized: Meinhard concentric glass nebulizer (CGN-A, JE Meinhard Associates, Inc., Santa Ana, CA, USA); microconcentric nebulizer (MCN) equipped with membrane desolvation system (Aridus, Cetac Technologies, Inc., Omaha, NE, USA); ultrasonic nebulizer with a membrane desolvation system (USN U-6000AT ${ }^{+}$, Cetac Technologies, Inc). Aqueous solutions were introduced in the continuous flow mode using a peristaltic pump (Perimax 12, Spetec GmbH, Erding, Germany). The ICP torch was shielded with a grounded platinum electrode (GuardElectrode ${ }^{(i x}$, Finnigan MAT).

Isotopic measurements were conducted at the Geological Survey of Israel with a double-focusing sector field MC-ICPMS with a forward Nier-Johnson geometry (Nu-Instruments, UK). For solution introduction a microconcentric nebulizer equipped with a desolvation system (Cetac Aridus) was used. Measurements at Northern Arizona University were conducted using a VG Axiom double focusing sector field MC-ICP-MS, operated in the single collector (electron multiplier) mode.
The Axiom MC-ICP-MS is equipped with a Cetac U-5000AT ultrasonic nebulizer with $5{ }^{\circ} \mathrm{C}$ water condenser, and is operated at an uptake rate of $0.5 \mathrm{~mL} \mathrm{~min}^{-1}$.

\section{Standards and reagents}

NIST standard reference materials U020, U350 and U500 (National Institute of Standards and Technology, USA) and solutions of uranium CCLU-500 (Laboratory Standard, Nuclear Research Center, Prague, Czech Republic ${ }^{36}$ ) were used for the optimization of isotope ratio measurement of uranium. Uranium isotope ratios for the CCLU-500 standard have been established $\left({ }^{234} \mathrm{U} /{ }^{238} \mathrm{U}=0.011122,{ }^{235} \mathrm{U} /{ }^{238} \mathrm{U}=\right.$ $\left.0.99991,{ }^{236} \mathrm{U} /{ }^{238} \mathrm{U}=0.002789\right)$ by calibration against the NIST-500 SRM using TIMS. Single-element standard stock solutions of $U$ and Th were obtained from Merck (Darmstadt, Germany). The solutions were diluted either with high purity deionized water (18 M $\Omega$ ), obtained from a Millipore Milli-QPlus water purifier (Millipore Bedford, MA, USA) or with deuterium oxide (obtained from Merck, purity 99.95\%) to the concentration of up to $100 \mathrm{ng} \mathrm{ml}^{-1}$ for determining the isotopic ratios of uranium and thorium by ICP-MS. All solutions were acidified to $1 \% \mathrm{HNO}_{3}$ with sub-boiled nitric acid. In case of dilution with $\mathrm{D}_{2} \mathrm{O}$, the final purity of deuterium after adding the standards and acidifying was $\sim 99.90 \%$.

\section{Samples and sample preparation}

Two samples with natural uranium isotopic pattern were received from Israel. Sample I was NIST SRM NBL112a pure uranium metal from the natural uranium mineral. Sample II was a natural uranium mineral pitchblende $\left(\mathrm{U}_{2} \mathrm{O}_{3}\right)$ from the precambrian mineralization in Timna mines, southern Israel. The investigated samples were diluted with heavy water.

\section{Optimization of ICP-SFMS and measurement protocol}

The Element ICP-MS instrument was optimized for maximum ${ }^{238} \mathrm{U}^{+}$signal and minimum background at $\mathrm{m} / \mathrm{z} 236 \mathrm{u}$ using a $1 \mathrm{ng} \mathrm{ml} \mathrm{m}^{-1} \mathrm{U}$ solution of natural isotopic composition. Instrument operation conditions are summarized in Table 1. Further details about the instrumentation and measurement procedure used are described elsewhere. ${ }^{27,37}$ The measured uranium isotopic ratio was corrected to account for $\mathrm{UH}^{+}$ formation, mass bias, and detector dead-time. The mass bias factor (assuming an exponential correction ${ }^{29}$ ) was determined using a $5 \mathrm{ng} \mathrm{ml}^{-1}$ NIST U500 standard solution as described elsewhere. ${ }^{28,38}$ A dead-time detector is of great importance for accurate measurements of isotope ratios and was calculated using the method described by Ketterer et al. ${ }^{39}$ The detector dead-time of the ICP-SFMS "Element" and the MC-ICP-MS "Axiom" were found to be $45 \mathrm{~ns}$ and $20 \mathrm{~ns}$, respectively.

\section{Results and discussion}

\section{Figures of merit of ICP-SFMS}

Abundance sensitivity of ICP-SFMS. Owing to molecular hydride formation of ${ }^{235} \mathrm{U}^{1} \mathrm{H}^{+}$and a strong peak tailing of ${ }^{238} \mathrm{U}^{+}$on mass $236 \mathrm{u}$ ICP-SFMS measurements at low mass resolution are not sufficient for accurate ${ }^{236} \mathrm{U} /{ }^{236} \mathrm{U}$ determination. In this work, in order to improve the abundance sensitivity of ICP-SFMS for ${ }^{236} \mathrm{U}$ measurements, the medium mass resolution mode $(m / \Delta m=4450)$ was applied.

For the ICP-SFMS (Element), the abundance at mass $236 \mathrm{u}$ was estimated based upon measurements performed with a ${ }^{232} \mathrm{Th}$ standard solution. All experimental parameters were first optimized in respect of the maximum of ${ }^{238} \mathrm{U}^{+}$ion intensity. A $0.1 \mu \mathrm{g} \mathrm{ml}^{-1}$ Th standard solution $\left({ }^{232} \mathrm{Th}\right.$ abundance $\left.100 \%\right)$ was used to obtain a statistically "true" peak tail for studying abundance sensitivity. This avoids measuring the combined 
Table 1 Optimized operation condition for ICP-SFMS and MC-ICP-MS with several sample introduction systems

\begin{tabular}{|c|c|c|c|c|c|}
\hline & \multicolumn{3}{|c|}{ ICP-SFMS (Element) } & \multirow{2}{*}{$\begin{array}{l}\text { MC-ICP-MS } \\
\text { Nu Plasma } \\
\text { Aridus }\end{array}$} & \multirow{2}{*}{$\begin{array}{l}\text { MC-ICP-MS } \\
\text { VG Axiom } \\
\text { USN }\end{array}$} \\
\hline & Meinhard & Aridus & USN & & \\
\hline Solution uptake rate/mL $\min ^{-1}$ & 0.58 & 0.1 & 2.0 & 0.08 & 0.50 \\
\hline Rf power/W & 1250 & 1100 & 1100 & 1300 & 1280 \\
\hline Cooling gas flow rate/L $\min ^{-1}$ & & 18 & & 13 & 13 \\
\hline Auxiliary gas flow rate/L $\mathrm{min}^{-1}$ & & 1.4 & & 1.1 & 0.85 \\
\hline USN heating temperature $/{ }^{\circ} \mathrm{C}$ & - & - & 140 & - & 140 \\
\hline USN cooling temperature $/{ }^{\circ} \mathrm{C}$ & - & - & 3 & - & 5 \\
\hline Spray chamber temperature $/{ }^{\circ} \mathrm{C}$ & - & 70 & - & 70 & 20 \\
\hline Desolvator heating temperature $/{ }^{\circ} \mathrm{C}$ & - & 160 & 160 & 160 & - \\
\hline Sweep gas flow/L $\min ^{-1}$ & - & 3.6 & 5.3 & 3.2 & - \\
\hline Extraction lens potential/V & & 2000 & & - & 4320 \\
\hline Mass window $(\%)$ & & 60 & & - & 150 \\
\hline Scanning mode & & Peak hopping & & - & E-scan, Peak jump \\
\hline
\end{tabular}

influences of ${ }^{235} \mathrm{U}^{+}$and ${ }^{238} \mathrm{U}^{+}$at $\mathrm{m} / \mathrm{z} 236$. In order to minimize the effect of other limiting factors, such as possible contamination of the blank and molecular ion formation, the abundance sensitivity for the isotope with mass $232.0375 \mathrm{u}$ for ${ }^{232} \mathrm{Th}$ was studied at masses $m \pm 0.5, m \pm 1.5, \mathrm{~m} \pm 2.5$, etc. This approach has the advantage that abundance sensitivity can be measured even when isobaric interferences are presented, so the peak tail is not affected by possible interferences at masses $m \pm 1 \mathrm{u}, m \pm 2 \mathrm{u}, m \pm 3 \mathrm{u}$, etc. Measured in medium resolution, the abundance ratio sensitivity for ${ }^{232} \mathrm{Th}$ is presented in Fig. 1. The intensity of the ${ }^{232} \mathrm{Th}^{+}$was $16 \mathrm{Mcps}$.

The abundance sensitivity for two mass units below the tailing peak in ICP-SFMS was calculated using eqn. 1.

Abundance sensitivity $\left(\frac{m}{m+2}\right)=\frac{\text { intensity on } m / z=230}{\text { intensity on } m / z=232}$

Besides the peak tailing from ${ }^{238} \mathrm{U}^{+}$, abundance sensitivity of

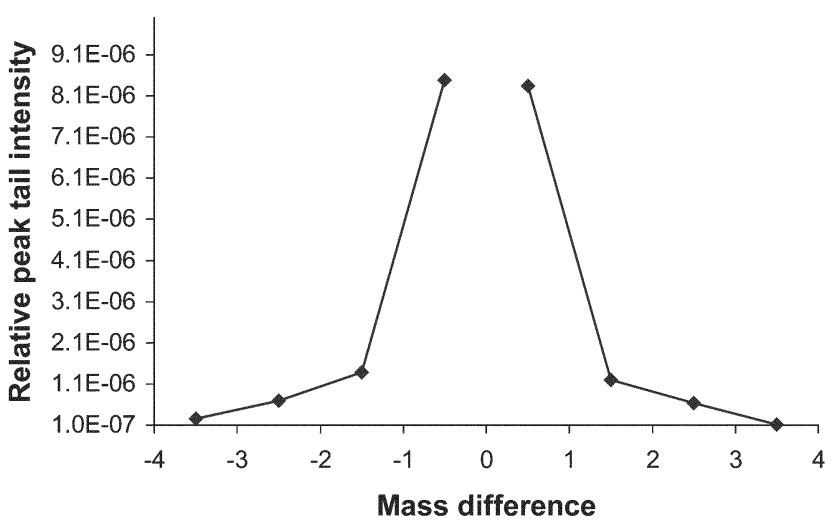

Fig. 1 Measured peak tail intensities at masses $m \pm x_{n}\left(x_{n}=0.5 \mathrm{u}\right.$, $1.5 \mathrm{u}$ and $2.5 \mathrm{u})$ to peak intensity at mass $m\left(m=232.0375 \mathrm{u}\right.$ for $\left.{ }^{232} \mathrm{Th}\right)$.
ICP-SFMS for ${ }^{236} \mathrm{U}$ determination with respect to ${ }^{235} \mathrm{U}^{+}$was also considered. Obtained values for two mass units below and one mass unit up the tailing peak were about $1.0 \times 10^{-6}$ and $4.8 \times 10^{-6}$, respectively (see Table 2 ). These values were further applied for the correction of ${ }^{236} \mathrm{U}^{+}$.

Sensitivity for uranium measurement and limit of detection. Sensitivities for uranium achieved on the ICP-SFMS in medium resolution mode using different nebulization system are summarized in Table 2. For the samples diluted with heavy water a maximum ${ }^{238} \mathrm{U}^{+}$intensity of $1770 \mathrm{Mcps}^{\mathrm{ppm}}{ }^{-1}$ was observed when the ultrasonic nebulizer with membrane desolvator was applied. About a one order of magnitude lower signal (200 $\mathrm{Mcps} \mathrm{ppm}^{-1}$ ) was obtained using Meinhard nebulizer. Application of a microconcentric nebulizer with the Aridus membrane desolvation system yielded an intensity about $400 \mathrm{Mcps}_{\mathrm{ppm}}{ }^{-1}$ for ${ }^{238} \mathrm{U}^{+}$. Approximately the same values were observed when for dilution of the samples Milli-Q water was used.

The detection limits of ${ }^{236} \mathrm{U}$ ( $3 \sigma$ of the blank on the mass $236 \mathrm{u}$ divided by the ${ }^{238} \mathrm{U}^{+}$ion intensity) calculated for different nebulization system are summarized in Table 2 . The lowest limit of detection of ${ }^{236} \mathrm{U}, 0.04 \times 1 \mathrm{fg} \mathrm{ml}^{-1}$, was achieved on the diluted with $\mathrm{D}_{2} \mathrm{O}$ samples when the Aridus nebulizer with desolvator was used.

In order to evaluate the capability of ICP-SFMS for determining the ${ }^{236} \mathrm{U} /{ }^{238} \mathrm{U}$ isotopic ratio, minimum detectable ratio criteria were applied (see eqn. 2).

$$
\begin{gathered}
\text { Minimum detectable }{ }^{236} \mathrm{U} /{ }^{238} \mathrm{U} \text { isotopic ratio }= \\
\frac{\text { signal on } m / z=236+3 \sigma}{\text { intensity on } m / z=238}
\end{gathered}
$$

Fig. 2 presents the minimum detectable ratio $(3 \sigma)$ for the ${ }^{236} \mathrm{U} /{ }^{338} \mathrm{U}$ isotopic ratio of uranium, for different nebulizers,

Table 2 Figures of merit of ICP-SFMS $(m / \Delta m=4450)$ for several solution introduction devices measured on the samples diluted with heavy

\begin{tabular}{|c|c|c|c|c|c|c|c|}
\hline & \multirow[b]{2}{*}{ 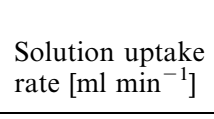 } & \multirow{2}{*}{\multicolumn{2}{|c|}{$\begin{array}{l}\text { Sensitivity of }{ }^{238} U \\
{\left[\mathrm{Mcps} \mathrm{ppm}^{-1}\right]}\end{array}$}} & \multirow[b]{2}{*}{$\begin{array}{l}\text { Uranium hydride } \\
\text { rate, } \mathrm{UH}^{+} / \mathrm{U}^{+}\end{array}$} & \multicolumn{2}{|c|}{ Abundance sensitivity } & \multirow[b]{2}{*}{$\begin{array}{l}\operatorname{LOD}(3 \sigma) \text { for }{ }^{236} \mathrm{U} \\
{\left[10^{-15} \mathrm{~g} \mathrm{ml}^{-1}\right]}\end{array}$} \\
\hline & & & & & $\frac{m-2}{m}$ & $\frac{m+1}{m}$ & \\
\hline \multicolumn{8}{|c|}{ Samples diluted with Milli-Q water } \\
\hline Meinhard & 0.58 & 205 & & $1.05 \times 10^{-4}$ & $1.06 \times 10^{-6}$ & $4.9 \times 10^{-6}$ & 0.41 \\
\hline USN with desolvator & 2.0 & 1800 & & $1.20 \times 10^{-5}$ & $0.98 \times 10^{-6}$ & $4.8 \times 10^{-6}$ & 0.16 \\
\hline Aridus & 0.1 & 400 & & $1.00 \times 10^{-5}$ & $0.98 \times 10^{-6}$ & $4.8 \times 10^{-6}$ & 0.13 \\
\hline \multicolumn{8}{|c|}{ Samples diluted with heavy water } \\
\hline Meinhard & 0.58 & 200 & & $6.05 \times 10^{-6}$ & $1.02 \times 10^{-6}$ & $4.8 \times 10^{-6}$ & 0.19 \\
\hline USN with desolvator & 2.0 & 1770 & & $1.10 \times 10^{-6}$ & $0.98 \times 10^{-6}$ & $4.8 \times 10^{-6}$ & 0.09 \\
\hline Aridus & 0.1 & 400 & & $9.02 \times 10^{-7}$ & $0.98 \times 10^{-6}$ & $4.8 \times 10^{-6}$ & 0.04 \\
\hline
\end{tabular}
water 


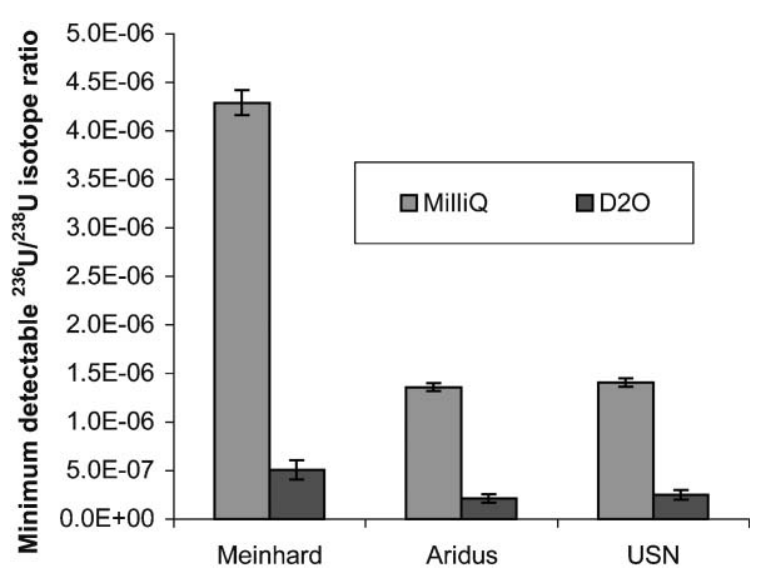

Fig. 2 Minimum detectable ratio criteria $(3 \sigma)$ for ${ }^{236} \mathrm{U} /{ }^{238} \mathrm{U}$ isotopic ratio of natural uranium for different nebulizers using $\mathrm{H}_{2} \mathrm{O}$ and $\mathrm{D}_{2} \mathrm{O}$ for dilution of the samples $(R=4450)$.

using Milli-Q and $\mathrm{D}_{2} \mathrm{O}$ waters for dilution of the samples. A decrease in the minimum detectable ratio about of one order of magnitude was observed for all nebulizers. The largest effect was found with a Meinhard nebulizer (because no desolvator is used) due to significant elimination of ${ }^{235} \mathrm{U}^{1} \mathrm{H}^{+}$ions when heavy water for dilution is used.

Precision and accuracy of isotopic ratio measurement. Precision and accuracy of the method for ${ }^{236} \mathrm{U} /{ }^{238} \mathrm{U}$ isotopic ratio measurement $(n=6)$ was determined on isotope standard reference materials CCLU-500 $\left({ }^{236} \mathrm{U}^{238} \mathrm{U}=0.002789\right)$ and NIST U-350 $\left({ }^{236} \mathrm{U} /{ }^{238} \mathrm{U}=0.002598\right)$ using different nebulization systems (see Table 3). A precision in the range $0.14-0.45 \%$ (RSD) was yielded when a Meinhard nebulizer was applied. An improvement of one order of magnitude is possible using MC-ICP-MS. ${ }^{40,41}$ Measured ${ }^{236} \mathrm{U} /{ }^{238} \mathrm{U}$ isotopic ratios were ranged from $2.778 \times 10^{-3}$ to $2.803 \times 10^{-3}$ whereby accuracies $-0.08 \%$ and $-0.07 \%$ were achieved for CCLU-500 diluted with Milli-Q and heavy waters, respectively.

In general, a small deterioration in precision and accuracy was observed, when for dilution of samples $\mathrm{D}_{2} \mathrm{O}$ water is used instead of Milli-Q water. This can be explained by insufficient acidification of heavy water that leads to adsorption of atoms of uranium on the walls of ICP parts and, therefore, less-stable solution introduction into the plasma.

Hydride formation rate of uranium. The hydride formation rate of uranium $\left(\mathrm{UH}^{+} / \mathrm{U}^{+}\right)$was studied in ICP-SFMS using $\mathrm{H}_{2} \mathrm{O}$ and $\mathrm{D}_{2} \mathrm{O}$ solvents. A typical ICP mass spectrum of uranium in the mass range of 237.5-241 u measured at medium mass resolution $(m / \Delta m=4450)$ for a $0.1 \mu \mathrm{g} \mathrm{ml}^{-1}$ solution of

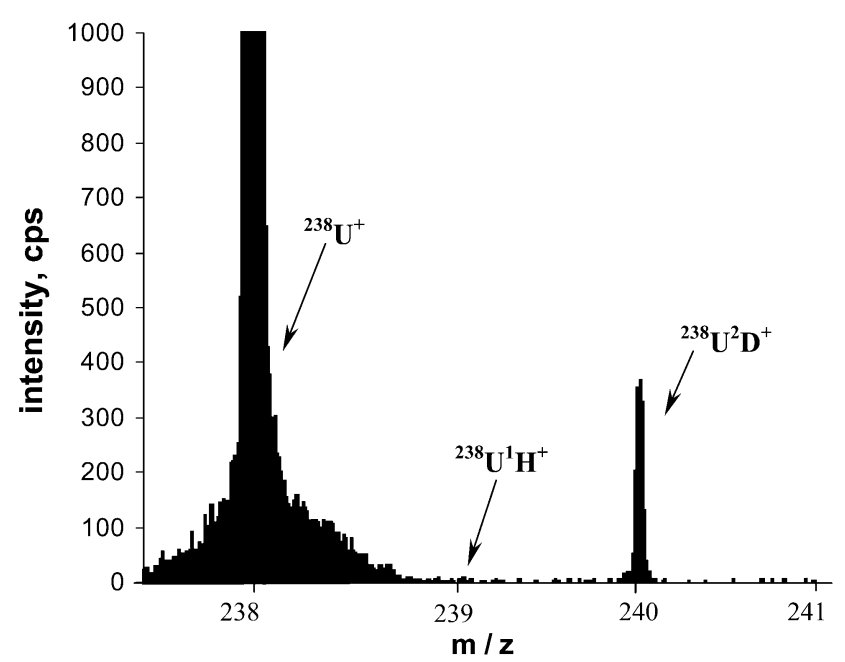

Fig. 3 ICP-MS spectrum of ${ }^{238} \mathrm{U}^{1} \mathrm{H}$ at mass resolution of 4450 measured for natural uranium, diluted with $\mathrm{D}_{2} \mathrm{O}$ using a Meinhard nebulizer.

uranium with natural isotope composition diluted in $\mathrm{D}_{2} \mathrm{O}$ is shown in Fig. 3. Instead of $\mathrm{UH}^{+}$at mass $239 \mathrm{u}$ (interferent in correct ${ }^{239} \mathrm{Pu}^{+}$measurements ${ }^{42}$, the formation of $\mathrm{UD}^{+}$ions was observed: therefore, using heavy water, the determination of ${ }^{240} \mathrm{Pu}$ will be disturbed. Results of the hydride formation rate $\mathrm{UH}^{+} / \mathrm{U}^{+}$for different nebulizers using Milli-Q and heavy waters are summarized in Table 2. In the case of Milli-Q water as solvent, application of an ultrasonic nebulizer with a microporous Teflon membrane desolvator allowed reduction of the $\mathrm{UH}^{+} / \mathrm{U}^{+}$ratio down to $1.20 \times 10^{-5}$, compared with $1.05 \times 10^{-4}$ for the Meinhard nebulizer (without desolvator). The lowest hydride formation rate $1.0 \times 10^{-5}$ was achieved with a microconcentric nebulizer with Aridus desolvator, reducing effectively the formation rate of uranium hydride ions $\mathrm{UH}^{+}$or possible isobaric interference of ${ }^{235} \mathrm{U}^{1} \mathrm{H}^{+}$on ${ }^{236} \mathrm{U}^{+}$by factor of ten in comparison with the Meinhard nebulizer.

Significant reduction of the hydride formation rate for the Meinhard nebulizer was found when, instead of Milli-Q water, $\mathrm{D}_{2} \mathrm{O}$ was applied for dilution of the samples. The obtained value of the $\mathrm{UH}^{+} / \mathrm{U}^{+}$ratio was $6.05 \times 10^{-6}$, which was almost two orders of magnitude lower than the hydride formation ratio, achieved with Milli-Q water. The lowest formation of uranium hydride molecular ions $\left[(9.02 \pm 0.3) \times 10^{-7}\right]$ was observed for the Aridus microconcentric nebulizer with membrane desolvator. The decreasing formation ratio for nebulizers with desolvators (USN and Aridus, 10 fold and 11 fold, respectively) is lower than for the Meinhard nebulizer (17 fold) for the samples diluted with heavy water. In our

Table 3 Results of ${ }^{236} \mathrm{U} /{ }^{238} \mathrm{U}$ isotopic ratios of uranium on CCLU-500 and NIST U350 standard reference materials diluted with Milli-Q and heavy water and their relative standard deviation $(n=6)$

\begin{tabular}{|c|c|c|c|c|c|}
\hline Standard reference material & Nebulizer & $\begin{array}{l}\text { Measured } \\
{ }^{236} \mathrm{U} /{ }^{238} \mathrm{U} \text { ratio }\end{array}$ & $\begin{array}{l}\text { RSD } \\
(\%)\end{array}$ & $\begin{array}{l}\text { Recommended } \\
{ }^{236} \mathrm{U} /{ }^{238} \mathrm{U} \text { ratio }\end{array}$ & $\begin{array}{l}\text { Accuracy } \\
(\%)\end{array}$ \\
\hline \multicolumn{6}{|l|}{ Dilution with Milli-Q water } \\
\hline \multirow[t]{3}{*}{ CCLU-500 } & Meinhard & $2.787 \times 10^{-3}$ & 0.26 & \multirow[t]{3}{*}{$2.789 \times 10^{-3}$} & -0.08 \\
\hline & Aridus & $2.777 \times 10^{-3}$ & 0.88 & & -0.42 \\
\hline & USN with desolvator & $2.775 \times 10^{-3}$ & 0.92 & & -0.49 \\
\hline \multirow[t]{3}{*}{ NIST U350 } & Meinhard & $2.594 \times 10^{-3}$ & 0.14 & \multirow[t]{3}{*}{$2.598 \times 10^{-3}$} & -0.15 \\
\hline & Aridus & $2.592 \times 10^{-3}$ & 0.36 & & -0.22 \\
\hline & USN with desolvator & $2.606 \times 10^{-3}$ & 1.01 & & 0.29 \\
\hline \multicolumn{6}{|l|}{ Dilution with heavy water } \\
\hline \multirow[t]{3}{*}{ CCLU-500 } & Meinhard & $2.787 \times 10^{-3}$ & 0.40 & \multirow[t]{3}{*}{$2.789 \times 10^{-3}$} & -0.07 \\
\hline & Aridus & $2.766 \times 10^{-3}$ & 0.96 & & -0.84 \\
\hline & USN with desolvator & $2.772 \times 10^{-3}$ & 1.19 & & -0.61 \\
\hline \multirow[t]{3}{*}{ NIST U350 } & Meinhard & $2.590 \times 10^{-3}$ & 0.45 & \multirow[t]{3}{*}{$2.598 \times 10^{-3}$} & -0.32 \\
\hline & Aridus & $2.585 \times 10^{-3}$ & 0.54 & & -0.50 \\
\hline & USN with desolvator & $2.630 \times 10^{-3}$ & 1.12 & & 1.23 \\
\hline
\end{tabular}


measurements was found (see Table 2) that even with application of nebulizers with a desolvation system (USN or Aridus) for measurement of the samples diluted with heavy water, the complete elimination of hydride formation is still not possible. The most probable reason for this could be a not " $100 \%$-pure" deuterium oxide solution (in present work 99.9\%) used for dilution samples. Moreover, the formation of hydride ions is caused by hydrogen, as well as water, which are presented as an impurity in argon and residue gas, respectively. Further study of this effect will be of interest in order to decrease the uranium hydride formation and, therefore, improve ability to detect ${ }^{236} \mathrm{U}$.

Experiments conducted using the Axiom ICP-SFMS also demonstrated significant diminution of the attenuation of $\mathrm{UH}^{+} / \mathrm{U}^{+}$in $\mathrm{D}_{2} \mathrm{O}$ solvent. The ratio ${ }^{238} \mathrm{U}^{1} \mathrm{H}^{+} / 238 \mathrm{U}^{+}$was measured for natural $\mathrm{U}$ solutions prepared in $\mathrm{H}_{2} \mathrm{O}$ and $\mathrm{D}_{2} \mathrm{O}$; the instrument was operated in the single collector (electron multiplier) mode with a mass resolution of $m / \Delta m=3450$. The $\mathrm{U}$ concentrations were adjusted to produce ${ }^{238} \mathrm{U}^{+}$signals of $\sim 1.2 \times 10^{6} \mathrm{cps}$; under these conditions the abundance sensitivity effects at $\mathrm{m} / \mathrm{z} 339$ are essentially negligible $(<1 \mathrm{cps}$ ), and the ${ }^{238} \mathrm{U}^{1} \mathrm{H}^{+} p^{238} \mathrm{U}^{+}$can be measured without influence from peak tails. Data were collected in $400 \mathrm{~s}$ blocks using a rapid electrostatic scanning program. These experiments revealed a ${ }^{238} \mathrm{U}^{1} \mathrm{H}^{+} /{ }^{238} \mathrm{U}^{+}$ratio of $(3.3 \pm 0.4) \times 10^{-5}(n=6)$ in $\mathrm{H}_{2} \mathrm{O}$ solution; in $\mathrm{D}_{2} \mathrm{O}$ solution a ${ }^{238} \mathrm{U}^{1} \mathrm{H}^{+} / 238 \mathrm{U}^{+}$ratio of $(1.1 \pm 0.1) \times 10^{-5}(n=16)$ was observed. This represents a highly significant three-fold decrease in $\mathrm{UH}^{+}$formation when $\mathrm{D}_{2} \mathrm{O}$ is used as the solvent. Ongoing work includes examining the potential for improvement in the determination of ${ }^{239} \mathrm{Pu}$ in $\mathrm{D}_{2} \mathrm{O}$ solvent, where the interference of ${ }^{238} \mathrm{U}^{1} \mathrm{H}^{+}$is a well known problem.

\section{${ }^{236} \mathrm{U} /{ }^{238} \mathrm{U}$ isotope ratio in natural samples from Israel}

The optimized method was applied for measurement of the ${ }^{236} \mathrm{U} /{ }^{238} \mathrm{U}$ isotopic ratio of two natural samples, received from Israel, which were diluted with heavy water. Comparative measurements were performed by ICP-SFMS and MC-ICPMS. All results are summarized in Table 4.

Measured by ICP-SFMS, ${ }^{236} \mathrm{U} /{ }^{238} \mathrm{U}$ isotopic ratios ranged from $(4.8 \pm 0.9) \times 10^{-7}$ to $(5.3 \pm 0.8) \times 10^{-7}$ and from $(6.5 \pm 1.2) \times 10^{-7}$ to $(7.4 \pm 1.5) \times 10^{-7}$ for samples I and II, respectively, whereas MC-ICP-MS measurements of ${ }^{236} \mathrm{U} /{ }^{238} \mathrm{U}$ isotopic ratio yielded $5.00 \pm 0.09 \times 10^{-7}$ for both samples.

\section{Conclusion}

This study evaluates the capability of ICP-MS to measure the ${ }^{236} \mathrm{U} /{ }^{238} \mathrm{U}$ isotope ratio of uranium down to the level of $10^{-7}$. In order to decrease the formation rate of $\mathrm{UH}^{+} / \mathrm{U}^{+}$samples were diluted with heavy water. The measured uranium hydride formation rate for samples diluted with $\mathrm{D}_{2} \mathrm{O}$ was about one order of magnitude lower for all nebulization systems in comparison with the samples diluted with conventional Milli-Q

Table $4{ }^{236} \mathrm{U} /{ }^{238} \mathrm{U}$ isotopic ratio in natural samples, received from Israel, diluted with heavy water and measured by ICP-SFMS using different nebulizers and by MC-ICP-MS with Aridus nebulizer

\begin{tabular}{|c|c|c|c|}
\hline Sample & ICP-MS & Nebulizer & $\begin{array}{l}\text { Measured }{ }^{236} \mathrm{U} /{ }^{238} \mathrm{U} \\
\text { isotopic ratio }\end{array}$ \\
\hline \multirow[t]{4}{*}{ I } & ICP-SFMS & Meinhard & $(5.3 \pm 0.8) \times 10^{-7}$ \\
\hline & & Aridus & $(4.8 \pm 0.9) \times 10^{-7}$ \\
\hline & & USN with desolvator & $(5.0 \pm 1.3) \times 10^{-7}$ \\
\hline & MC-ICP-MS & Aridus & $(5.00 \pm 0.08) \times 10^{-7}$ \\
\hline \multirow[t]{4}{*}{ II } & ICP-SFMS & Meinhard & $(7.1 \pm 0.9) \times 10^{-7}$ \\
\hline & & Aridus & $(6.5 \pm 1.2) \times 10^{-7}$ \\
\hline & & USN with desolvator & $(7.4 \pm 1.5) \times 10^{-7}$ \\
\hline & MC-ICP-MS & Aridus & $(5.00 \pm 0.09) \times 10^{-7}$ \\
\hline
\end{tabular}

water. Instead of $\mathrm{UH}^{+}$, formation of $\mathrm{UD}^{+}$was observed. The abundance sensitivity of ICP-MS was improved using the medium mass resolution mode in comparison to low mass resolution. Measurement of ${ }^{236} U /{ }^{238} \mathrm{U}$ isotopic ratio in standard reference materials diluted with heavy water showed good accuracy and low relative standard deviation. Further study will be of interest to decrease the minimum hydride formation rate, using for acidification of the solution deuterium-based acid, e.g., $\mathrm{D}_{2} \mathrm{NO}_{3}$.

\section{Acknowledgements}

The authors from Germany and Israel would like to thank the Bundesministerium für Bildung und Forschung (BMBF) for financial support of the bilateral BMBF-MOST cooperation in Water Technology.

M.E.K. acknowledges support from the US National Science Foundation for funds to purchase the Axiom sector ICPMS (MRI Grant CHE-0116804).

\section{References}

1 J. S. Becker, J. Anal. At. Spectrom., 2002, 17, 1172-1185.

2 C. Bouvier-Capely, N. Baglan, A. Montegue, J. Ritt and C. Cossonnet, Health Phys., 2003, 85, 216-219.

3 R. S. Pappas, B. G. Ting, J. M. Jarrett, D. C. Paschal, S. P. Caudill and D. T. Miller, J. Anal. At. Spectrom., 2002, 17, 131-134.

4 S. F. Boulyga, J. L. Matusevich, V. P. Mironov, V. P. Kudrjashov, L. Halicz, I. Segal, J. A. McLean, A. Montaser and J. S. Becker, J. Anal. At. Spectrom., 2002, 17, 958-964.

5 M. E. Ketterer, K. M. Hafer, C. L. Link, C. S. Royden and W. J. Hartsock, J. Environ. Radioact., 2003, 67, 191-206.

6 D. Desideri, M. A. Meli, C. Roselli, C. Testa, S. F. Boulyga and J. S. Becker, Anal. Bioanal. Chem., 2002, 376, 1091-1095.

7 O. J. Marsden, F. R. Livens, J. P. Day, L. K. Fifield and P. S. Goodall, Analyst, 2001, 126, 633-636.

8 M. Hotchkis, D. Child, D. Fink, G. Jacobsen, P. Lee, N. Mino, A. Smith and C. Tuniz, Nucl. Instrum. Method. Phys. Res. B, 2000, 172, 659-655.

9 S. Richter, A. Alonso, W. De Bolle, R. Wellum and P. D. P. Taylor, Int. J. Mass Spectrom., 1999, 193, 9.

10 D. Berkovits, N. Feldstein, S. Ghelberg, A. Hershkowitz, E. Navon and M. Paul, Nucl. Instrum. Meth. Phys. Res. B, 2000, 172, 372-376.

11 P. Steier, R. Golser, W. Kutschera, A. Priller, C. Vockenhuber and V. Liechtenstein, Nucl. Instrum. Meth. Phys. Res. B, 2002, 188, 283-287.

12 S. F. Boulyga, C. Testa, D. Desideri and J. S. Becker, J. Anal. At. Spectrom., 2001, 16, 1283-1289.

13 R. Pollanen, T. K. Ikaheimonen, S. Klemola, V. P. Vartti, K. Vesterbacka, S. Ristonmaa, T. Honkamaa, P. Sipila, I. Jokelainen, A. Kosunen, R. Zilliacus, M. Kettunen and M. Hokkanen, J. Environ. Radioact., 2003, 64, 133-142.

14 P. R. Danesi, A. Blaise, W. Burkart, T. Cabianca, M. J. Campbell, M. Makarewicz, J. Moreno, C. Tuniz and M. Hotchkis, J. Environ. Radioact., 2003, 64, 121-131.

15 G. Kirchner and C. Noack, Nucl. Saf., 1988, 29, 1.

16 Fission Product Transport Processes in Reactor Accidents, eds. S. N. Begichev, A. A. Borovoj, E. B. Burlakov, A. J. Gagarinsky, V. F. Demin, A. A. Khrulev and I. L. Khodakovsky, Hemisphere, New York, 1990.

17 A. M. Sanczes, F. V. Tome, J. D. Bejarano and M. J. Vargas, Nucl. Instrum. Meth., 1992, A313, 219.

18 J. P. McLaughlin, L. L. Vintro, K. J. Smith, P. I. Mitchell and Z. S. Zunic, J. Environ. Radioact., 2003, 64, 155-165.

19 J. S. Becker, Spectrochim. Acta, Part B, 2003, 58, 1757-1784.

20 S. K. Sahoo, S. Kimura, Y. Watanabe, K. Shiraishi and A. Masuda, Proc. Jpn Acad., Ser. B, 2002, 78, 196-200.

21 K. G. Heumann, Mass Spectrom. Rev., 1992, 11, 41.

22 I. T. Platzner, Modern Isotope Ratio Mass Spectrometry, John Wiley, Chichester, 1997.

23 L. K. Fifield, Nucl. Instrum. Meth. Phys. Res. B, 2000, 172, 134.

24 M. Paul, D. Berkovits, I. Ahmad, F. Borasi, J. Caggiano, C. N. Davids, J. P. Greene, B. Harss, A. Heinz, D. J. Henderson, W. Henning, C. L. Jiang, R. C. Pardo, K. E. Rehm, R. Rejoub, D. Seweryniak, A. Sonzogni, J. Uusitalo and R. Vondrazek, Nucl. Instrum. Meth. Phys. Res. B, 2000, 172. 
25 A. Montaser, Inductively Coupled Plasma Mass Spectrometry, Wiley-VCH, New York, 1998.

26 Mass Spectrometry of Long-Lived Radionuclides in Encyclopedia of Analytical Chemistry, eds. J. S. Becker and H.-J. Dietze, John Wiley, 2000.

27 J. S. Becker and H.-J. Dietze, Fresenius' J. Anal. Chem., 2000, 368, 23-30.

28 K. G. Heumann, S. M. Gallus, G. Radlinger and J. Vogl, J. Anal. At. Spectrom., 1998, 13, 1001-1008.

29 P. D. P. Taylor, P. De Bievre, A. J. Walder and A. Entwistle, J. Anal. At. Spectrom., 1995, 10, 395.

30 S. F. Boulyga and J. S. Becker, Fresenius' J. Anal. Chem., 2001, 370, 612 .

31 M. Thirwall, J. Anal. At. Spectrom., 2001, 16, 1121.

32 S. Turner, P. van Calsteren, N. Vigier and L. Thomas, J. Anal. At. Spectrom., 2001, 16, 612-615.

33 D. A. Solyom, O. A. Gron, J. H. Barnes and G. M. Hieftje, Spectrochim. Acta, Part B, 2001, 56, 1717-1729.
34 S. F. Boulyga and J. S. Becker, J. Anal. At. Spectrom., 2002, 17, 1202-1206.

35 S. F. Boulyga, J. S. Becker, J. L. Matusievich and H.-J. Dietze, Int. J. Mass. Spectrom., 2000, 203, 143-154.

36 H.-J. Dietze, Ber. Zent. Isotopen Strahlenforsch. Akad. Wiss. DDR, 1979.

37 J. S. Becker and H.-J. Dietze, J. Anal. At. Spectrom., 1999, 14, 1493.

38 C. P. Ingle, B. L. Sharp, M. S. A. Horstwood, R. R. Parrish and D. J. Lewis, J. Anal. At. Spectrom., 2003, 18, 219-229.

39 M. E. Ketterer, J. A. Jordan, S. C. Szechenyi, D. D. Hudson and R. R. Layman, J. Anal. At. Spectrom., 2000, 15, 1569-1573.

40 D. Malinovsky, A. Stenberg, I. Rodushkin, H. Andren, J. Ingri, B. Ohlander and D. C. Baxter, J. Anal. At. Spectrom., 2003, 18, 687-695.

41 I. T. Platzner, S. Ehrlich and L. Halicz, Fresenius' J. Anal. Chem., 2001, 370, 624.

42 I. Rodushkin, P. Lindahl, E. Holm and P. Roos, Nucl. Instrum. Meth. Phys. Res. B, 1999, A423, 472-479. 